Article

\title{
Social Sustainability in Adolescents' Music Event Attendance
}

\author{
Maarit Kinnunen ${ }^{1, * \mathbb{D}}$, Harri Homi ${ }^{2}$ and Antti Honkanen ${ }^{1} \mathbb{D}$ \\ 1 Multidimensional Tourism Institute, University of Lapland, P.O. Box 122, 96300 Rovaniemi, Finland; \\ antti.honkanen@ulapland.fi \\ 2 LiveFIN, Näsilinnankatu 22 A 28, 33210 Tampere, Finland; harri.homi@gmail.com \\ * Correspondence: maarkinn@ulapland.fi
}

Received: 10 October 2020; Accepted: 10 November 2020; Published: 12 November 2020

\begin{abstract}
This study focuses on social sustainability of music events in adolescents' lives through their perceptions and own words as they describe their live music experiences. Scrutinizing music event attendance from the social sustainability perspective demonstrates that the cultural content per se is not as meaningful as the social network that comes together in such events. The research questions were: How is social sustainability manifested in adolescents' music event attendance, and what are the implications? The research data comprised the results of a web survey directed at 15-18 year old adolescents. Bonding and bridging, as well as the sense of community, were present in adolescents' descriptions of live music experiences, producing various forms of well-being effects. The sense of belonging was almost missing from the narratives, which suggests that how adolescents consume music has a decaying interest in the grassroots culture that fosters the sense of belonging. This has major implications for the development of popular culture.
\end{abstract}

Keywords: adolescents; social sustainability; event attendees; music events; music festivals; well-being

\section{Introduction}

Music is an essential part of adolescents' lives as a building block in identity construction [1,2]. It also offers a means to evaluate others and find like-minded friends, as well as demonstrate one's values [3]. Attending live music events adds social dimensions to music consumption. The sense of community is a well-recognized aspect of music events, as attendees celebrate together and develop a temporary emotional "we mode" through their bodily expressions during the musical performances $[4,5]$. Additionally, the sense of belonging is a fundamental constituent of musical scenes, since fans of certain musical genres or subcultures are sometimes stigmatized in the outside world [6]. Inside their music scene, they construct an enclave where they feel approved and safe. Furthermore, music events offer opportunities to bond with friends and get acquainted with new ones. It is a part of growing up to become independent and create social networks external to one's family. We define these various social dimensions and their impacts as social sustainability in the context of music event attendance.

We will focus on social sustainability of music events in adolescents' lives through their perceptions and own words as they describe their live music experiences. The research questions were: How is social sustainability manifested in adolescents' music event attendance and what are the implications? The research data comprised the results of a web survey directed at 15-18 year old Finnish adolescents. The survey included both structured and open-ended questions concentrating on adolescents' opinions and experiences of live music events.

Research on the social sustainability of events concentrates on social impacts on local residents [7]. Studies on the social dimensions of the most important stakeholder group, event attendees, tend to 
focus on participation motivations [8], whereas our emphasis is on the outcome of social sustainability in music event attendance. Events and festivals are important social practices, but still, the use of the conceptualization of social sustainability in event attendance studies is rare [9]. Interpretation of events' social dimensions within the scope of sustainability helps in understanding the positive impacts of event attendance, like feelings of safety, social identity building, and other aspects of well-being $[2,6,10]$. Scrutinizing music event attendance from the social sustainability perspective demonstrates that the cultural content per se is not as meaningful as the social network that comes together in such events.

Adolescents' music consumption has mainly been studied from the viewpoints of social concern or well-being [11-13]. Even though the social dimensions of music events have positive effects on individual young attendees, we try to see the bigger picture regarding the development of popular culture. Thus, adding knowledge on social sustainability of adolescent music event attendance, we also aim to discuss the meaning of social sustainability for the evolution of popular (music) culture.

\section{Literature Review}

\subsection{Social Sustainability}

There are conceptualizations that attempt to define social sustainability; examples include: "Social sustainability is: a positive condition within communities, and a process within communities that can achieve that condition" [14] (p. 23), and "Social sustainability can be interpreted as a condition and process within the community that fulfills the basic human needs in addition to the principles of social justice and equity, homogeneity and cohesion, integration, diversity, sense of place, social amenity, and social security for the present generation, while guaranteeing them for the future generations" [15] (p. 31). They demonstrate the difficulty of conceptualizing social sustainability and the strength of the tendency to measure it with different indicators.

Equity, employment, education, social justice, basic needs, and poverty alleviation have been components of the "hard" or traditional definition of social sustainability $[16,17]$. However, over the last couple of decades, "soft" elements have gained more attention, and themes such as quality of life, happiness, participation, identity, pride, sense of place, social mixing, social capital, social leverage, social cohesion, integration, and diversity $[9,16-18]$ have been defined as constituents of social sustainability. The variation of topics involved demonstrates the challenging nature of defining social sustainability unambiguously, but it is clear that social sustainability is firmly related to well-being [19]. Åhman emphasizes that social sustainability should be treated "as a cluster of sub-concepts, themes, and indicators rather than as one single concept" [17] (p. 1158). All in all, the concept should be approached in a context-sensitive way, since different contexts have different emphases. For instance, urban development projects aim at different outcomes in terms of social sustainability compared with tourism strategies. We aim to focus on social sustainability in the context of music events.

\subsection{Social Sustainability in Event Attendance}

Studies on the social sustainability of events tend to concentrate on social impacts on local residents. These include empowerment of the local community in the process of organizing events that nurture pride in place and community cohesiveness, diversified cultural supply due to the events, and identification of the richness and importance of local culture [20-23]. On the negative side, there is the inappropriate behavior of event attendees disturbing local residents [24,25]. However, research on social sustainability from the point of view of event attendees-locals or non-locals-is scarcer. Many studies refer to different aspects of event sociality, but explicit interpretations of these social dimensions as social sustainability are rare.

In terms of social sustainability, event attendance is considered to add social connections in the forms of bonding, bridging, sense of community, and sense of belonging, as summarized in Table 1 . Bonding and bridging in the event context mean enhancing social networks, often defined as social capital [26]. They are developed on an individual-to-individual level by having personal and mainly 
long-term social connections with each other. In the sense of community, sociality is perceived to embrace all of the event participants, that is, familiar faces and strangers, the audience, and musicians and event workers. The feeling of the sense of community lasts only for the duration of the event, even though it is frequently reminisced about after the event, and is consequently a major motivation for participation. The sense of belonging, on the other hand, is a long-term state of mind that is connected to other people - both known and strangers-who feel connected due to a shared interest. Next, we will review event studies concerning these aspects of social sustainability.

Table 1. Dimensions of social sustainability in the event context.

\begin{tabular}{cc}
\hline Dimension & Characteristics \\
\hline Bonding [8,27-30] & $\begin{array}{c}\text { Spending time with friends and family (known-group socialization); } \\
\text { Creating shared memories }\end{array}$ \\
\hline Bridging [8,27-29] & Making new friends (external socialization) \\
\hline Sense of community [8,18,30-33] & $\begin{array}{c}\text { A temporary and spatially restricted liminoid zone facilitates a } \\
\text { strong sense of collectiveness with other participants } \\
\text { (audience socialization); }\end{array}$ \\
$\begin{array}{c}\text { Shared enjoyment, collective actions and emotions } \\
\text { Sense of belonging [30] }\end{array}$ & $\begin{array}{r}\text { Longer-lasting communities demonstrating a shared social identity } \\
\text { with shared values and beliefs; } \\
\text { for instance, refugees or ethnic minority immigrants [34], } \\
\text { or residents of a rural countryside [35], but also communities of fans } \\
\text { of a musician, band, musical genre, or subculture }\end{array}$ \\
\hline
\end{tabular}

Quinn and Wilks [27-29] use Putnam's [36] social capital terms of bonding and bridging. They define event bonding as known-group socializing-sharing time at an event with friends and family - whereas event bridging involves connections with people who one did not know before and who normally "move in different circles" [28] (p. 27).

Nordvall et al. [8] divide event socialization into three types: known-group, external, and audience socialization. Known-group socialization is spending time with friends and family, whereas external socialization means meeting new people. Audience socialization is defined as "being part of the collective experience or $(\ldots)$ interactions with other visitors (anonymous, not friends or family) comprising the audience" [8] (p. 137).

Chalip [18], using the term social value, concentrates on the sense of community that is related to Nordvall et al.'s audience socialization. Events are liminoid zones where everyday rules and social hierarchy do not apply $[37,38]$. Within a specific time and space, event attendees, organizers, performers, and volunteers form a tolerant and egalitarian communitas [39] that is more open to social interactions than the surrounding society [28]. Shared enjoyment [31], as well as collective actions [32] and collective emotions [33], is typical for these communitas.

Rihova et al. [30] combine social capital and social value in event and festival sociality, defining their perspective as socially constructed, co-created value. They divide social practices into bonding, communing, and belonging practices. Using social capital terminology, they define bonding as spending quality time, sharing experiences, and creating long-lasting memories with friends and family. Communing practices, on the other hand, refer to Chalip's social value, meaning that the liminoid space at events or festivals creates an extraordinary temporary communitas where participants can act free from the surrounding society's rules and restrictions. This creates "strong, if only temporary, social links among complete strangers" [30] (p. 79) and an escape from mundane routines. Finally, belonging practices are connected to a shared interest, like fandom for an artist or dedication to a subculture, and events offer opportunities to demonstrate "a shared social identity with specific values and beliefs" [30] (p. 79).

The division between the sense of community and the sense of belonging is important. The sense of community -in the event context-is a temporary sensation that normally lasts only the duration of the 
event, whereas the sense of belonging is a more long-lasting — not necessarily permanent—connection that people feel towards other people that have similar values and interests. Interestingly, the sense of belonging might involve people who have not met each other at all. For instance, fans have a strong feeling of unity by being members of the same "tribe" [40] due to a shared interest that might be a musician [41] or a musical genre [42].

\subsection{Social Sustainability and Adolescents}

Social sustainability of events is important to all event attendees, but our focus is on adolescent, 15-18 year old music event attendees. This attendee group and the live music context add interesting viewpoints on social sustainability.

Music is an important ingredient in young people's lives, since it involves opportunities to elaborate on emotions and identities [2,5,43]. It offers an easy way to process the strong emotions that are often part of growing up. Identifying oneself as a member of a (fan) community helps in having "the feeling of belonging or of sharing a sense of personal relatedness" [44] (p. 9). Adolescents rate people with similar musical taste positively [3], and a sense of belonging can even be achieved when listening to music alone [45]. However, attending a live music event adds to the communal feeling, as there are lots of like-minded people who share the same musical interests and demonstrate shared emotions in the form of dancing and singing along [46,47].

Having fun and creating shared memories with friends belong to youth and increase feelings of independence. Festival attendance-connected sometimes with extensive use of alcohol-is a traditional rite of passage to adulthood among western youth [48]. Additionally, young event attendees are interested in getting to know new people [10]. One reason is to find new, like-minded friends outside the family and school, but also the natural desire to find a partner in a romantic and sexual sense. In the present study, we aim to identify and discuss different social dimensions of music event attendance at a young age.

It is also important to note that other types of events-like live attendance of sports-in the roles of both spectator and participant nurture socialities. However, the importance of music is overwhelming in teenagers' lives. In Finland, in 2017, daily music listening increased from 50\% to 82\% and annual concert attendance from $48 \%$ to $60 \%$ in the age groups of 10-14 and 15-19, respectively [49]. Across the same age groups, daily sports activities decreased from $51 \%$ to $34 \%$ in the summer, and from $32 \%$ to $25 \%$ in the winter [49]. This means that the line between being a child and a teenager, as well as the increasing influence of friends instead of family during growing up, can be seen in the exploding consumption of music. This makes music event attendance particularly interesting in terms of social dimensions, besides the fact that social sustainability in adolescents' music event participation has not been studied to such an extent as with adults, who form most music event audiences. Adolescents were, on average, 10\% of Finnish music festival attendees in 2019 [50], but information about the proportion of adolescent participants in other live music venues is not available.

Finnish adolescents' live music consumption has increased throughout the current millennium, and the trend is towards attendance at bigger concerts [49]. These typically are concerts of national (Children of Bodom, Cheek) and international stars (Ed Sheeran, Lil Pump), not grassroots DIY music events. This has consequences for the future of popular music culture and will also be discussed in the present paper.

\section{Materials and Methods}

LiveFIN, the network and interest group of Finnish music events, conducted a web survey about 15-18 year olds, inquiring about their live music consumption. The sample was a self-selected one, meaning that after seeing the invitation in social media, potential respondents decided whether to participate or not. In Finland, minors who are at least 15 years old are allowed to participate in research independently, without their parents' consent [51]. Since the participation in the survey was voluntary and all the participants were at least 15 years old, the ethical preconditions were fulfilled. 
The survey was distributed by 23 youth-related organizations in November-December 2019 and, altogether, 1328 valid responses were received from adolescents who had attended live music events. As an incentive, the respondents could take part in a prize draw of ten gift vouchers worth $€ 50$ each.

The demographics of the respondents are summarized in Table 2. Respondents' mean and median ages were 16.8 and 17 years, respectively, and quite naturally, most of them (84\%) were full-time students. A total of $34 \%$ of respondents lived in a large city with over 100,000 inhabitants, while $50 \%$ lived in a smaller city and $15 \%$ in the rural countryside.

Table 2. Demographics of respondents $(N=1328)$.

\begin{tabular}{cccc}
\hline Variable & Classification & Frequeency & $\%$ \\
\hline \multirow{2}{*}{ Gender } & Male & 277 & $20.9 \%$ \\
& Female & 1029 & $77.5 \%$ \\
Other & 10 & $0.8 \%$ \\
Age (mean 16.8 years & Do not want to answer & 12 & $0.9 \%$ \\
median 17 years) & 15 years & 183 & $13.8 \%$ \\
& 16 years & 295 & $22.2 \%$ \\
& 17 years & 405 & $30.5 \%$ \\
Residence & 18 years & 445 & $33.5 \%$ \\
\hline Situation in life & Large city (over 100,000 inhabitants) & 457 & $34.4 \%$ \\
& Medium-sized city (50,000-100,000 inhabitants) & 399 & $30.0 \%$ \\
& Small town (less than 50,000 inhabitants) & 271 & $20.4 \%$ \\
& Rural countryside & 201 & $15.1 \%$ \\
\hline & I am studying & 1116 & $84.0 \%$ \\
& I am working and studying & 167 & $12.6 \%$ \\
& I am working & 25 & $1.9 \%$ \\
& I am unemployed & 7 & $0.5 \%$ \\
& Other & 13 & $1.0 \%$ \\
\hline & I am still attending comprehensive school & 209 & $15.7 \%$ \\
& Comprehensive school & 566 & $42.6 \%$ \\
& Upper secondary school & 325 & $24.5 \%$ \\
& Vocational school & 183 & $13.8 \%$
\end{tabular}

Of the respondents, $77 \%$ were female, $21 \%$ were male, and $2 \%$ were other or did not want to specify their gender, meaning that there was a bias towards female respondents, which is typical for research surveys $[52,53]$. This bias should be discussed further. According to the Official Statistics of Finland, in the 15-19 age group in 2017, 87\% of females and $74 \%$ of males had attended a concert at least once in their life [49]. We included in the study only those respondents who had attended live music events. When non-attendees were included, the proportion of male respondents was $27 \%$, meaning that in non-attendees, there were more males than females. Those adolescents who did not attend gigs listened to music - $49 \%$ of them even daily-but the live music experience was not suitable or attractive for them, due to, for example, crowding, the high volume of music, and noise produced by attendees.

The survey was mainly distributed via social media (Facebook, Instagram, WhatsApp), which caused part of the bias, since there are more female users of social media, and they also spend more time using social media than males [54]. Among the distributors, there were five club venues, four large festivals, and several organizations offering music education and rehearsal spaces, which means that young males interested in music were-at least in principle-approached. Furthermore, among the distributors of the survey, there was a parkour association and an ice-hockey 
team that presumably attracted male adolescents. However, parkour or ice-hockey enthusiasts do not necessarily have much time for other hobbies and might have been non-attendees in the study.

The importance of music for adolescents was truly clear: $87 \%$ of respondents listened to music or watched music videos nearly daily. The only thing that was a more popular pastime was communicating with friends using the internet or by phone ( $89 \%$ nearly daily).

The questionnaire included various questions about live music attendance: types of live music events attended, company in them, reasons for attending, where to find information about music events, what is important in gigs and concerts, what makes a good gig, and what might increase attendance in music events. The background questions included questions about hobbies and pastimes as well as socio-demographics, as described in Table 2.

Two judges conducted content analysis [55] for the answers to the open-ended question on attendance motives ("Why do you attend gigs/concerts?"), which comprised 14,835 words in Finnish and Swedish. First, one judge classified the first 100 and the other one the last 100 answers. Based on these results, the categories were consolidated and defined. After that, both judges classified all the answers in a spreadsheet independently of each other, and the results were transferred to IBM SPSS version 25 to enable statistical analysis. The percentage of agreement was $92.98 \%$. The relationship between the participation motives and company in gigs and concerts was tested by chi-square tests. This way, we were able to define different further qualities of social sustainability in music event attendance. For instance, widening one's social capital by making new friends when attending alone is a combination that explains some of the well-being effects from the social sustainability point of view.

\section{Results}

The essence of different social dimensions in attending music events was present when asked with whom adolescents went to gigs and concerts (Figure 1-grouped by company type). The most popular choice was close friends ( $94 \%$ of respondents), demonstrating the outstanding meaning of social practices in the event context. The next most important group was schoolmates $(47 \%)$, followed by parents $(36 \%)$, a larger group $(35 \%)$, siblings $(32 \%)$, and attending alone $(19 \%)$. The significance of workmates and grandparents was marginal.

\section{With whom do you attend gigs / concerts? You can choose various options.}

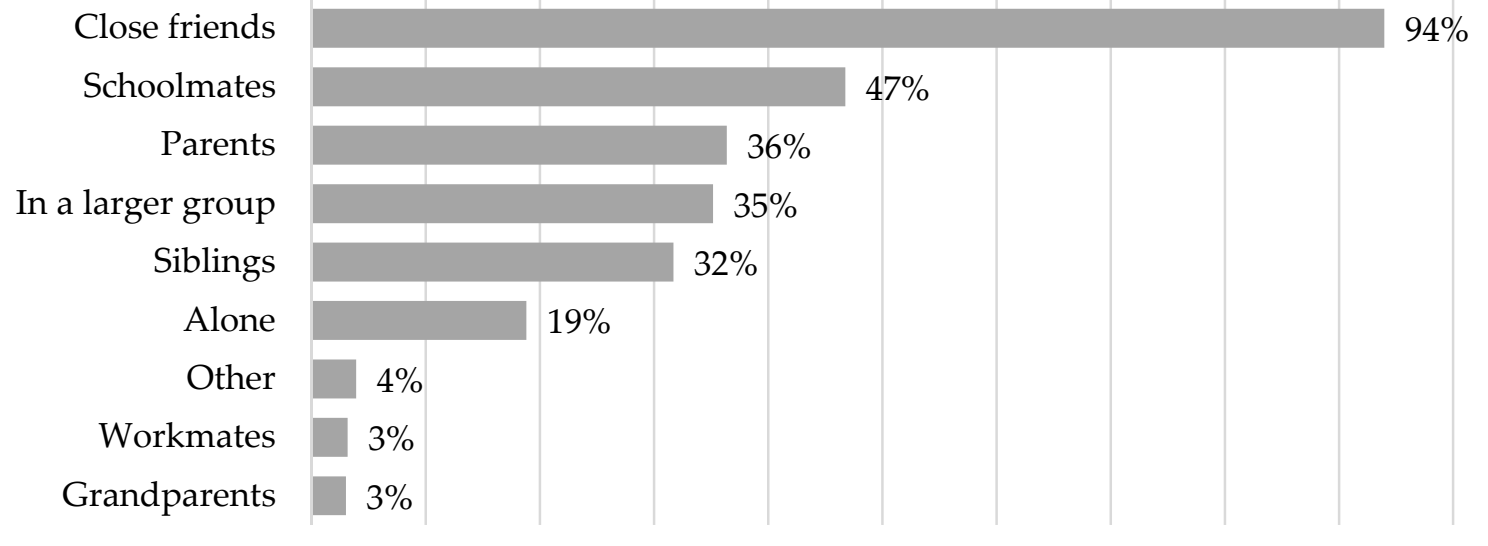

Figure 1. Company in gigs and concerts $(N=1328)$.

The open-ended question "Why do you attend gigs/concerts?", with 1108 answers, represented participation motives. The content of the responses was analyzed and placed into 16 categories (Figure 2). The atmosphere in gigs was the most frequent answer (39\%), followed by the importance of music (likes music, 35\%; likes live music, $28 \%$ ). These top three motives do not explicitly carry 
elements of social sustainability, but they contain social meanings. Atmosphere is a multifaceted concept, where one dimension is the social atmosphere generated by the positive and active attitude of the audience. Music, on the other hand, is the core context of music events, and often the primary reason to participate. Illustrations like "Music is therapy for my brain, especially in the middle of everyday life full of stress" (female, 18) and "Music is very important for me, it has been like that since I was a toddler. I listen to music every day" (female, 16) described the meaning of music for respondents, confirming the results of studies that emphasize the essence of music in adolescence $[2,3,12]$.

\section{Why do you attend gigs / concerts?}

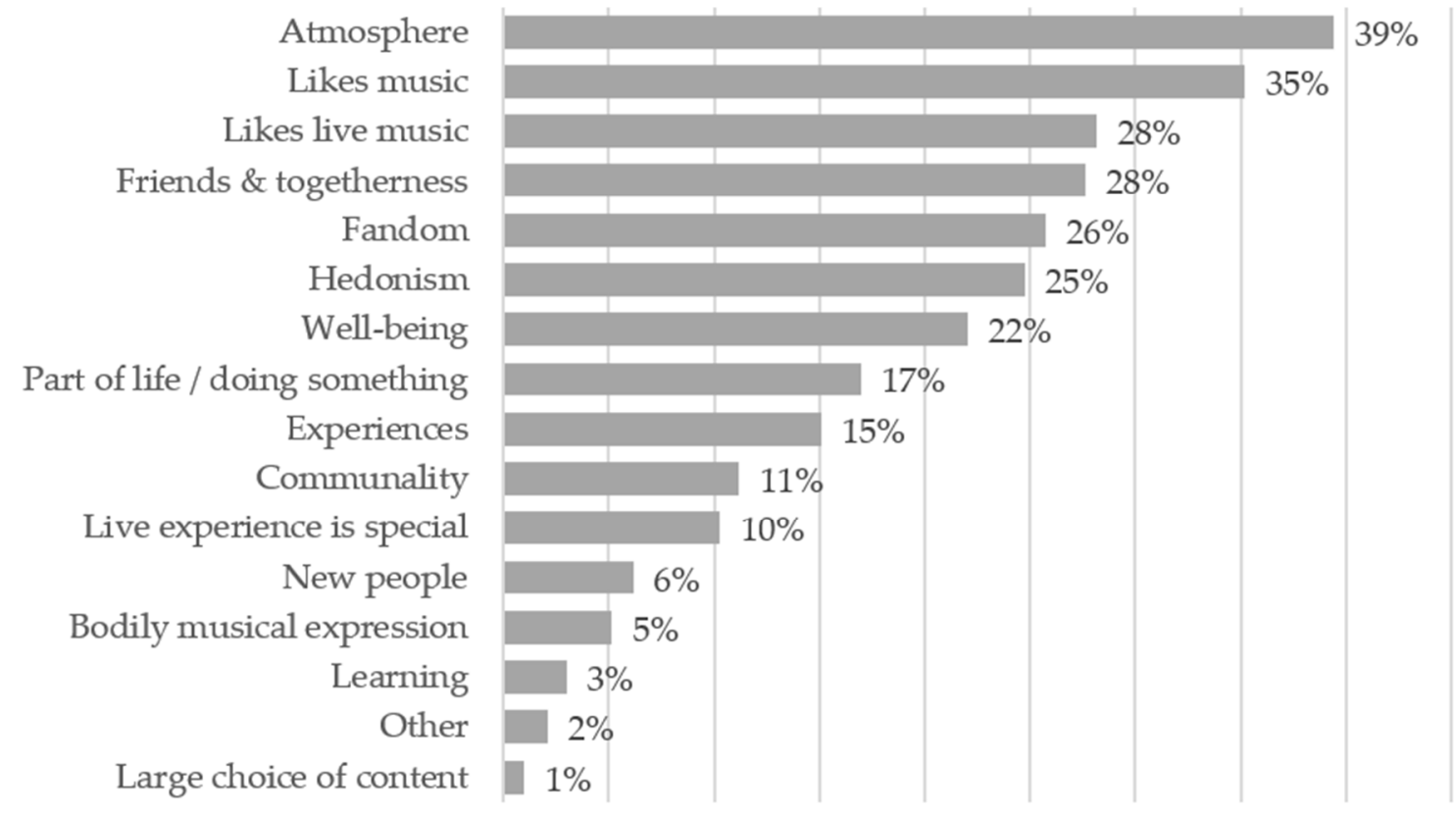

Figure 2. Motivations for attending gigs/concerts $(N=1108)$.

It is important to see the difference between music and live music. In live music events, the reactions and activities of fellow participants add a perspective of sociality to the live show offered by musicians ("I love the feeling and atmosphere in all kinds of gigs and festivals. The music and the sense of well-being of people is always reflected to others", female, 16). It is noteworthy that adolescents differentiated music and live music, and specifically identified live music as an important element of their attendance; for example, this comment: "Best feeling, I love live music, dancing and singing along. It is great to see your favorite artist live!" (female, 16). The urge for seeing one's favorite artist in a live performance was present in motivational descriptions, even though the idol was usually not named. When considering different musical genres, rap, metal, and K-pop were mentioned, but only a couple of times, since they were not specifically asked about. Nevertheless, it was possible to discern that live music attendance was driven by an interest in specific music content.

However, there were only very few signs of gatherings focused on music representing a marginal culture or scene, or another social network. These did not emerge as pull factors for live music events to the same extent as for older generations. Instead, it seemed that adolescents' music attendance was focusing on consuming specific content or an experience related to music performance, instead of stakeholding or ownership of the event. The drive towards the content aligns with the studies of consumerization of childhood [56], where certain products are manufactured and marketed specifically for young consumers. Therefore, packaging adolescents' desire to consume music as a product is a fact, but earlier, there was a solid, small portion of young people who were oriented toward going to clubs, which fostered a certain marginal or grassroots culture. According to ticket sales, this juvenile group is currently diminishing [57]. 
The most frequent explicitly social aspect in attendance motivations was the presence of friends (friends and togetherness, 28\%). Examples of this category included comments like "And of course I want to spend quality time with my friends $\bigcirc$ " (male, 17 years) and "Shared nice time with friends" (male, 17). Fandom for an artist or a certain musical genre was present in $26 \%$, and hedonism-having fun and celebrating - was present in $25 \%$ of answers. Well-being effects were recognized by $22 \%$ of respondents: "You get a nice feeling and can forget all the everyday worries" (male, 18). Taking part in gigs was seen as a natural part of young life and as offering something to do in free time (17\%), as well as an opportunity to have special experiences (15\%). Enjoying communality was identified in $11 \%$ of answers; for instance: "Even though you would not know anyone there, you feel approved and equal to others" (female, 16) and "I can enjoy my greatest passion in a good and like-minded lot. Having been bullied, the communality at gigs creates a new and valuable meaning in life. The sense of community is always incredible" (female, 16). Live music experience was considered something special by $10 \%$ of respondents. Meeting new people and making friends was important in $6 \%$ of answers; "I have also made friends through gigs, and so nowadays, one important reason to attend gigs is to meet friends I would not otherwise see so often" (female, 17). Finally, bodily musical expression (dancing or singing along) was important for $5 \%$, learning new things about music for $3 \%$, and large choice of content (typically in festivals) for $1 \%$ of the respondents.

It should be noted that many answers included various motivational factors; hence, the categories used were not mutually exclusive. For example, the answer "Gigs and concerts give you something to expect for the whole year. You always have lots of fun, regardless of the weather. Friends and music make it. You'll never know what kinds of nice things will happen or whether you will make new friends. You should not miss out on that kind of thing at this age": (female, 15) was classified into several categories (hedonism, friends and togetherness, new people, likes music, experiences, and a part of life).

Motivation categories and company are cross-tabulated in Table 3. In the table, "Yes" means that the open-ended answer about participation motive was included in the category. Consequently, "No" does not mean that the respondent explicitly denied that the category influenced the decision to attend, but it was not a motivation that came to mind in the first instance. Company is included in the table only if the motivation category was present ("Yes") and there was a statistically significant correlation $(p<0.05)$ between the motivation category and company. The findings are logical and interesting.

Liking live music was most important when attending alone or with family members. Particularly in the case of attending alone, this implies that the meaning of live music was so high that it facilitated the participation decision regardless of the absence of company. This was supported by the importance of artist or genre fandom, as well as learning something new when attending alone.

Hedonism and attending gigs as a part of life were strongest when attending with schoolmates or in a larger group. It seems that hedonistic pleasures required a larger set of people [58]. Furthermore, attending gigs in the company of schoolmates or in a larger group was a part of adolescent life by creating memories when celebrating together with people of the same age.

The motivational factor of friends and togetherness was self-evidently connected to the company of friends, schoolmates, and a larger group, whereas meeting new friends was a meaningful motivation for participation when attending alone or in a larger group. Getting acquainted was important when attending alone, since other members of the audience liked a similar kind of music, and this offered the possibility to get to know other fans. When attending in a larger crowd, adolescents might not know all the members of the group beforehand, and meeting new people may refer to getting acquainted with these people. Nevertheless, meeting new people when attending a gig in a larger crowd might also mean that the person in question was very social, and it was thus natural to socialize at gigs.

Interestingly, communality was present only when attending with parents. The general infrequency of communality does not mean that it would have been present only when attending gigs with parents. Rather, communality is not as easily recognizable as the atmosphere, which undoubtedly has communal aspects. We will return to the sense of community in the Discussion section. 
Table 3. Attendance motivation (classified answers to the open-ended question: "Why do you attend gigs/concerts?") vs. company (structured question: “With whom do you attend gigs/concerts?"), $N=1108$.

\begin{tabular}{|c|c|c|c|c|c|c|}
\hline \multirow{2}{*}{$\begin{array}{c}\text { Motivation } \\
\text { Company (below, in Italics) }\end{array}$} & & \multicolumn{2}{|c|}{$\%$} & \multicolumn{2}{|c|}{ Frequency } & \multirow{2}{*}{ Chi-Square } \\
\hline & & No & Yes & No & Yes & \\
\hline Atmosphere & & $60.6 \%$ & $39.4 \%$ & 671 & 437 & \\
\hline Likes music & & $64.8 \%$ & $35.2 \%$ & 718 & 390 & \\
\hline Likes live music & & $71.8 \%$ & $28.2 \%$ & 796 & 312 & \multirow{3}{*}{$4.16 p=0.041$} \\
\hline \multirow{2}{*}{ With siblings } & No & $73.8 \%$ & $67.9 \%$ & 546 & 250 & \\
\hline & Yes & $26.2 \%$ & $32.1 \%$ & 194 & 118 & \\
\hline \multirow{2}{*}{ With parents } & No & $74.0 \%$ & $68.1 \%$ & 521 & 275 & \multirow{2}{*}{$4.47 p=0.034$} \\
\hline & Yes & $26.0 \%$ & $31.9 \%$ & 183 & 129 & \\
\hline \multirow{2}{*}{ Alone } & No & $73.7 \%$ & $64.2 \%$ & 658 & 138 & \multirow{2}{*}{$7.73 p=0.005$} \\
\hline & Yes & $26.3 \%$ & $35.8 \%$ & 235 & 77 & \\
\hline Friends and togetherness & & $72.4 \%$ & $27.6 \%$ & 802 & 306 & \multirow{3}{*}{$9.45 p=0.002$} \\
\hline \multirow{2}{*}{ With close friends } & No & $89.1 \%$ & $71.4 \%$ & 57 & 745 & \\
\hline & Yes & $10.9 \%$ & $28.6 \%$ & 7 & 299 & \\
\hline \multirow{2}{*}{ With schoolmates } & No & $76.5 \%$ & $67.9 \%$ & 442 & 360 & \multirow{2}{*}{$10.10 p=0.001$} \\
\hline & Yes & $23.5 \%$ & $32.1 \%$ & 136 & 170 & \\
\hline \multirow{2}{*}{ With parents } & No & $68.8 \%$ & $78.7 \%$ & 484 & 318 & \multirow{2}{*}{$12.75 p=0.000$} \\
\hline & Yes & $31.3 \%$ & $21.3 \%$ & 220 & 86 & \\
\hline \multirow{2}{*}{ Alone } & No & $69.9 \%$ & $82.8 \%$ & 624 & 178 & \multirow{2}{*}{$14.46 p=0.000$} \\
\hline & Yes & $30.1 \%$ & $17.2 \%$ & 269 & 37 & \\
\hline In a larger group & No & $77.2 \%$ & $64.2 \%$ & 538 & 264 & $21.71 p=0.000$ \\
\hline In a larger group & Yes & $22.8 \%$ & $35.8 \%$ & 159 & 147 & $21 . / 1 p=0.000$ \\
\hline Fandom & & $74.3 \%$ & $25.7 \%$ & 823 & 285 & \\
\hline & No & $76.9 \%$ & $63.3 \%$ & 687 & 136 & \\
\hline Alone & Yes & $23.1 \%$ & $36.7 \%$ & 206 & 79 & $16.90 p=0.000$ \\
\hline Hedonism & & $75.3 \%$ & $24.7 \%$ & 834 & 274 & \\
\hline & No & $78.2 \%$ & $72.1 \%$ & 452 & 382 & $5.57 p=0.018$ \\
\hline With schoolmates & Yes & $21.8 \%$ & $27.9 \%$ & 126 & 148 & $0.57 p=0.018$ \\
\hline & No & $72.7 \%$ & $79.7 \%$ & 512 & 322 & \\
\hline With parents & Yes & $27.3 \%$ & $20.3 \%$ & 192 & 82 & $0.71 p=0.010$ \\
\hline & No & $73.2 \%$ & $83.7 \%$ & 654 & 180 & \\
\hline Alone & Yes & $26.8 \%$ & $16.3 \%$ & 239 & 35 & $10.23 p=0.001$ \\
\hline In a laroer oroun & No & $78.5 \%$ & $69.8 \%$ & 547 & 287 & $1039 n=0001$ \\
\hline In a larger group & Yes & $21.5 \%$ & $30.2 \%$ & 150 & 124 & $10.09 p=0.001$ \\
\hline Well-being & & $78.0 \%$ & $22.0 \%$ & 864 & 244 & \\
\hline Part of life & & $83.0 \%$ & $17.0 \%$ & 920 & 188 & \\
\hline & No & $85.8 \%$ & $80.0 \%$ & 496 & 424 & \\
\hline With schoolmates & Yes & $14.2 \%$ & $20.0 \%$ & 82 & 106 & $6.63 p=0.010$ \\
\hline In a larger group & No & $85.4 \%$ & $79.1 \%$ & 595 & 325 & $7.26 p=0.007$ \\
\hline In u turger group & Yes & $14.6 \%$ & $20.9 \%$ & 102 & 86 & $7.20 p-0.007$ \\
\hline Experiences & & $84.9 \%$ & $15.1 \%$ & 941 & 167 & \\
\hline Communality & & $88.8 \%$ & $11.2 \%$ & 984 & 124 & \\
\hline With parents & No & $90.3 \%$ & $86.1 \%$ & 636 & 348 & $4.56 n=0.033$ \\
\hline Wom parents & Yes & $9.7 \%$ & $13.9 \%$ & 68 & 56 & $4.00 p=0.030$ \\
\hline Live experience is special & & $89.7 \%$ & $10.3 \%$ & 994 & 114 & \\
\hline New people & & $93.9 \%$ & $6.1 \%$ & 1040 & 68 & \\
\hline & No & $94.7 \%$ & $90.2 \%$ & 846 & 194 & $6.10 p=0.013$ \\
\hline Alone & Yes & $5.3 \%$ & $9.8 \%$ & 47 & 21 & $0.10 p=0.013$ \\
\hline In a laroer oroun & No & $95.4 \%$ & $91.2 \%$ & 665 & 375 & $780 n=0.005$ \\
\hline In a targer group & Yes & $4.6 \%$ & $8.8 \%$ & 32 & 36 & $7.00 p=0.000$ \\
\hline Bodily musical expression & & $94.9 \%$ & $5.1 \%$ & 1051 & 57 & \\
\hline Learning & & $97.0 \%$ & $3.0 \%$ & 1075 & 33 & \\
\hline & No & $97.5 \%$ & $94.9 \%$ & 871 & 204 & $4.22 n=0.040$ \\
\hline Alone & Yes & $2.5 \%$ & $5.1 \%$ & 22 & 11 & $4.22 p=0.040$ \\
\hline Large choice of content & & $99.0 \%$ & $1.0 \%$ & 1097 & 11 & \\
\hline
\end{tabular}




\section{Discussion}

\subsection{Social Sustainability in Adolescents' Music Event Attendance}

We aimed to scrutinize the dimensions of social sustainability in a context-sensitive way, focusing on adolescents' music event attendance. It is emphasized that the meaning of music is very important for adolescents, and it helps particularly in coping with the difficult situations related to growing up. However, we will concentrate here on the social dimensions of music event attendance, which were described in the Literature Review section. Bonding and bridging, as well as a sense of community, were explicitly present in adolescents' descriptions of live music experiences. Interestingly, the sense of belonging was nearly non-existent and needed more interpretation.

The social dimensions found in adolescents' music event attendance are similar to the ones in the adult population. The social aspects identified in the literature were detected in the adult context, and this study confirms that the same ones are found among adolescents. Naturally, the company in adults' event attendance is oriented towards partners, friends, and children, whereas adolescents' company includes schoolmates, grandparents, parents, and siblings. However, the sense of belonging is found in studies of adult music event attendance, particularly in the context of metal or punk events [42,59], but it is missing from adolescents' narratives.

\subsubsection{Bonding}

Bonding [8,27-30]—-that is, spending quality time with friends and family-was present in adolescents' narratives of attendance motives. The relationship to friends and schoolmates was strongest, since adolescence is also about creating one's social networks outside the family. In particular, there was a group of respondents who did not want to spend time with members of their family in festivals and concerts, but preferred enjoying live music with their friends.

Bonding meant having hedonistic fun with friends: drinking and celebrating together, enjoying their youth, and creating shared memories in a larger group of schoolmates and other friends. Experiencing good feelings with friends at a concert was related to recovery, regaining strength, and deepening social bonds, which function on the surface of societal well-being. However, bonding also included a lack of diversity, since strong groups of friends might often share the same musical taste and have similar values, ethnicity, cultural background, and social class $[29,60]$.

\subsubsection{Bridging}

Bridging [8,27-29] meant making new friends, not just occasional socializing with strangers. This included both getting acquainted by chance, but also intentionally seeking new friends. A music-loving adolescent attending alone wanted to get acquainted with others that had the same musical interests. Getting acquainted with new people is particularly important for people involved in a certain musical subgenre, for whom the most important friendships may be built outside school. One reason for searching for social contacts external to school might be bullying that is experienced at school, as the quote of a female respondent indicated. Sometimes, bullying is present because of the clothing and hairstyle typical of the musical subculture in question, stigmatizing its fans [6].

People attending gigs in a larger group demonstrated a desire to get to know new people. Participating with several people showed a certain kind of sociality that was carried on during the event. Finally, we should not forget the importance of romance. At a young age, the first significant other is often found at a music event, where the liminal environment facilitates social contacts [28]. Building up social networks increases social capital, which is an essential part of social sustainability, as indicated particularly in Wilks' and Quinn's studies [27-29].

\subsubsection{Sense of Community}

Studies have consistently shown that listening to recorded music helps with processing and expressing emotions at the subjective level [11,61-63], but live music has very particular capabilities in 
producing a setting where emotions are processed, experienced, and expressed together $[4,46,64,65]$. This can be described as "we mode", or shared emotional connection $[44,66]$ that culminates in the social atmosphere of live music events. Thus, the event atmosphere is not created solely by the official program, lights, and sound, but also by the audience (social atmosphere) [8].

Empowerment that is achieved from shared or co-experienced emotions produces a sense of community $[8,18,30-33]$. This feeling is achieved in events limited in time and space, and it is one of the major pull factors of events and festivals. In adolescents' motivational factors, this was implied in the choices of atmosphere, liking live music, and communality. Nevertheless, the sense of community per se was not recognized as easily as the atmosphere, which might stem from the difficulty of identifying communal aspects [67].

Participants wanted to relive the social atmosphere and sense of community by regularly attending gigs. They were aware that leaving the everyday worries behind and entering a temporary event community that aimed to interact positively with others and have fun together increased their well-being through hedonism, recovery, and stress relief [30]. The social sustainability of the sense of community culminated in these temporary well-being effects.

\subsubsection{Sense of Belonging}

The possibility to meet like-minded people can function as a non-normative social space that is enabled in the context of live music events (cf. [28]). This kind of space enables socialities, identities, and social conventions that everyday life does not contain. Additionally, the everyday environment might even include physical threats if a marginal identity is expressed at school or elsewhere in the outside world. The emergent social space at events of a certain musical genre or subculture allows networks to express their sociality and identity freely and creates a strong sense of belonging [30], facilitating safe self-expression and emotional attachment [35]. For instance, gay [68] or punk clubs [59] are undeniably venues for an expression of identity that has no other (public) means. Here, the value lies in the event and the social space around it instead of the musical content only. Frequent attendance at the same club might encourage participating alone, since the place becomes familiar and safe. Some clubs offer adolescents possibilities to do volunteering as a form of participation in the associated scene. This increases ownership, the place identity [20], and the sense of inclusion [34], but also activates adolescents in the co-production of popular culture in the long run [69].

The sense of belonging produces emotional connection and works as a constituent of shared social identity [19]. These factors differ from the sense of community by transgressing temporary event time boundaries and extending to everyday life. This difference is significant from the social sustainability point of view because there are more options to feel social belonging and, therefore, less chance for the social ill-being that stems from the lack of it.

Live music events that foster a sense of belonging can be seen to operate in the structures of society by enabling a multiplicity of social norms and identities. Temporary, event-related bonding and a sense of community are important for social life, but from the social sustainability standpoint, they function at the "end of the pipe", alleviating stress and anxiety without curing the cause [70]. When dealing with complex problems such as social exclusion, the intervention should challenge the system structures that produce the problems in the first place. That is, the long-term impact comes from preventing social ill-being that might happen without a sense of belonging.

It is of utmost importance to note that the sense of belonging was practically missing from the adolescents' narratives. There were only very infrequent references to the DIY music culture or active involvement in any musical scene. The DIY ethos was essential, for instance, in the formation of punk, metal, and rap cultures [71], which also gave opportunities to create long-term careers in music [72]. However, there have been changes in the musical tastes of youth. In 2017, the most popular musical genres among Finnish adolescents were (in this order): (1) pop or rock, (2) rap, pop-rap, and hip-hop, (3) electronic dance music and techno, (4) easy listening and schlager, and (5) heavy metal [49]. Heavy metal, which created an incredible boom of Finnish metal bands, has been extremely 
popular in Finland, but its popularity, especially among children, has been steadily decreasing since the monster metal band Lordi won the Eurovision Song Contest in 2006. Rap has taken its place in teenagers' playlists, but its DIY culture is not present to the same extent as it was in the rise of the popularity of metal. The present study gives alarming indications that young people's use of music is increasingly turning towards pure consumption and lacking production aspects of popular music culture. The scarcity of the sense of belonging suggests that how adolescents consume music has a decaying interest towards the grassroots culture that fosters the sense of belonging. This has major implications for the development of popular culture.

\subsection{Implications for the Development of Popular (Music) Culture}

We should see the diversity of the adolescent live music scene as being as important as that of the adult live music scene. We should even see it as more important because, firstly, identities enabled by the social networks gathering around the music can have a significant impact on adolescents' lives, and secondly, music consumption that coordinates socialities is in a transitional stage now that digital music consumption is more common among adolescents than adults [49]. To be more precise, Spotify and YouTube have replaced the role of physical records in commercializing music by unlocking the music distribution from its physical restraints and from the economy surrounding the record industry. Recorded music distribution is no longer mediated geographically by groups of actors such as radio, record shops, TV, and print media, but by streaming services that are capable of delivering music as a product [73]. The new digital music consumption model is not based on buying the ownership of a record, but instead on buying access rights to a vast music library.

Digitalization is focusing music consumption and discovery into fewer channels that have a vast selection of music, but-and this is important-the consumption is also coordinated and controlled by these few channels. In the industrial era, consumers had to rely on available information channels that were modulated by a multiplicity of social, political, and cultural factors. This picture changed radically when such boundaries were abolished and information channels became global. As a result, commercial music offerings do not need to address any certain social or cultural particularities, and national characteristics are easily replaced by global ones. The economics of the streaming platforms must address the low-profit margin of digitally distributed music and, therefore, seek a larger consumer base to sustain their business position [74]. This leads to development where the dominant path is product-oriented, which does not lead to diversity nor socially oriented popular music culture.

As a result, bigger artists draw more attention on globally shared platforms. Attention focusing on bigger artists is also likely to drive bigger events, which, again, may not be the venues for social multiplicity or ones that allow and empower divergent socialities to emerge. This tendency may be even stronger among juveniles than adults because they do not have much spending power. For instance, the freemium music streaming model that is very popular among young people is financed by third-party advertisers and operates with a significantly smaller profit margin than the paid premium listening model. In practice, this means that when making music for young listeners who are using the freemium model, the reach of the music needs to be much wider than for paid listeners, thus making juvenile music consumption more interwoven into economies of scale.

The commercialization of childhood has a long history, but previously, juvenile consumption was financed by parents [75], therefore making parents agents in identity formation mediated by consumerism. In the current digital streaming consumption mode, a significant part of media offers are sponsored by third (commercial) parties, thus rendering the juvenile decision-making a more autonomous act [56]. At the same time, adolescents are primarily using streaming services for music listening [49]. Therefore, it becomes difficult, if not impossible, particularly for children, to remain untouched by the continuous exposure to socio-cultural ideals portrayed by market-driven music consumption. This setup seems not the most desirable in the scope of social sustainability because sustainability must be defined to include meeting human physical, emotional, and social needs. 
The context of digitally recorded music consumption and the embedded economic models do not meet these terms yet.

The long-term effects of the developing music consumption model remain undisclosed, but the importance of social sustainability created by the sense of belonging needs to be taken into account when evaluating the social value of live DIY and grassroots music culture and how they are present in popular music culture. The challenge in third-party-sponsored juvenile music consumption is that it might hamper the initial discovery of the grassroots culture at a young age. How can socialities that do not scale and that do not have economic significance remain fertile in a context where volume matters? Similarly, when juvenile consumption is being driven more directly by juveniles themselves, the mediation of non-monetary and social values can have less meaning. The challenge in the contemporary consumption environment is: How can a grassroots culture that would attract and activate adolescents be created in order to develop a sense of belonging, which is an essential element of sustainable well-being?

The present study concentrated merely on physical attendance of live music events. The outbreak of COVID-19 in the spring of 2020 accelerated two types of development that were also available before the pandemic, but were not so well known: virtual presence and virtual reality. Since artists were unable to perform for live audiences during the COVID-19 lockdown, live streaming of gigs became an essential method to offer live music combined with a digital presence. Live music was streamed online from a venue without an audience present. The space shared by artists and the audience was a digital social media platform, usually YouTube or Facebook. In addition to performing together in a specific venue and having a virtual audience, the performers might also have been present virtually. In this scenario, each artist made a video of their own part beforehand in different locations, mainly at home, and the virtual band, orchestra, or choir was combined into a single video with each performer in their own window. This type of performance required post-editing, since the separate videos had to be pieced together and synchronized. While the digital space offered a way to listen to music and watch its performance, it was still limited in terms of the social presence that the platforms had to offer. In particular, the social interaction was limited to sending comments in a chat discussion or liking the stream or video.

In parallel to virtual presence in gigs broadcast or distributed on social media platforms, there have also been concerts in virtual reality (VR). VR is known from video games and it has extended to music performances, especially during the COVID-19 ban of gigs with live audiences. On the eve of May Day 2020, over half a million Finns watched a virtual reality gig of the popular rap duo JVG, and as many as 150,000 avatars were "present" in the virtual Senate Square of Helsinki [76]. Another example was the small Naamat rock festival that was arranged using 360-degree cameras, offering livestreamed gigs and the possibility to wander around the festival area. During the festival visit, one could chat with other attendees in different locations. In VR, it is also possible that each attendee has a unique visual experience that they can tailor during the concert, as well as having a visual experience that cannot be produced in reality [77].

Adolescents are experienced users of VR environments due to their active involvement in video gaming, which makes them good candidates for VR concert attendance. New models and tools for experiencing digital live music are constantly under construction. The tendency to enhance the event experience has extended to platforms available on the web, and the COVID-19 pandemic accelerated this development. Many of those who attended live streaming or VR gigs during the lockdown will probably continue to follow these opportunities as techniques and practices improve. It will be interesting to see if physical gigs will be combined with live streaming to a larger extent in the future. In this context, the kinds of social presence and social networks that will be available inside new forms of live music events are essential, since mere spectatorship will not be enough, but participants will expect possibilities for socializing and co-creation of their event experiences. There is a lot of potential, considering that virtual and physical presence can be combined by virtually following a gig with a group of friends that is physically present in someone's home. 
Emerging forms of virtual live music experiences are accompanied by the change of music-making culture, as artists and creatives alike have the capability to produce music independently of the production companies that were necessary partners in the 20th century. Artists no longer need to have year-long careers, build large networks, and get commercial companies interested in their music. Quite the opposite is true; one can jump-start a career from a bedroom studio and become an immediate global phenomenon. New social spaces offered by social media have blurred the line between producer and artist by reshaping how music is shared. For example, all the music shared on YouTube or SoundCloud is also capable of attracting likes and messages, which get embedded into the social presence of performers. Recorded music distributed via social media has the capabilities as well as the restraints of user-created content.

The most recent developments in music and social media platforms have allowed peer-to-peer (P2P) networks to develop creative interpretations and remixes of third-party content. On TikTok, which is exceptionally popular among adolescents, anyone can create videos where they perform on top of someone else's piece of music, thus creating their own unique content. Hence, the value of certain music content decreases, whereas the value of the interpretations created by peers increases. It looks like there is development towards a lower threshold of being an artist, but at the same time, fewer small artists are performing live. It will be interesting to see if other measures of success will emerge than just the size of the network, and if this form of production will nourish a musical culture that fosters a sense of belonging.

Author Contributions: All authors contributed equally to this work. All authors have read and agreed to the published version of the manuscript.

Funding: The project was managed by LiveFIN and was funded by the Finnish Ministry of Education and Culture.

Conflicts of Interest: The authors declare no conflict of interest.

\section{References}

1. Frith, S. Sound Effects: Youth, Leisure, and the Politics of Rock'n'n'roll; Pantheon: New York, NY, USA, 1981.

2. Nuttall, P. Insiders, regulars and tourists: Exploring selves and music consumption in adolescence. J. Consum. Behav. 2009, 8, 211-224. [CrossRef]

3. North, A.C.; Hargreaves, D.J. Music and adolescent identity. Music. Educ. Res. 1999, 1, 75-92. [CrossRef]

4. Kelly, J.R.; Iannone, N.E.; McCarty, M. The function of shared affect in groups. In Collective Emotions: Perspectives from Psychology, Philosophy, and Sociology; von Scheve, C., Salmela, M., Eds.; Oxford University Press: Oxford, UK, 2014; pp. 175-188.

5. Turino, T. Music as Social Life: The Politics of Participation; University of Chicago Press: Chicago, IL, USA, 2008.

6. Henry, P.C.; Caldwell, M. Self-empowerment and consumption: Consumer remedies for prolonged stigmatization. Eur. J. Mark. 2006, 40, 1031-1048. [CrossRef]

7. Van Winkle, C.M.; Woosnam, K.M. Sense of community and perceptions of festival social impacts. Int. J. Event Festiv. Manag. 2014, 5, 22-38. [CrossRef]

8. Nordvall, A.; Pettersson, R.; Svensson, B.; Brown, S. Designing events for social interaction. Event Manag. 2014, 18, 127-140. [CrossRef]

9. Quinn, B. Festivals and social sustainability. In The Routledge Handbook of Festivals; Mair, J., Ed.; Routledge: London, UK, 2019; pp. 53-61.

10. Packer, J.; Ballantyne, J. The impact of music festival attendance on young people's psychological and social well-being. Psychol. Music 2011, 39, 164-181. [CrossRef]

11. Papinczak, Z.E.; Dingle, G.A.; Stoyanov, S.R.; Hides, L.; Zelenko, O. Young people's uses of music for well-being. J. Youth Stud. 2015, 18, 1119-1134. [CrossRef]

12. Saarikallio, S.; Vuoskoski, J.; Luck, G. Adolescents' expression and perception of emotion in music reflects their broader abilities of emotional communication. Psychol. Well-Being 2014, 4, 21. [CrossRef]

13. Wright, R. "I'd sell you suicide": Pop music and moral panic in the age of Marilyn Manson. Pop. Music 2000, 19, 365-385. [CrossRef] 
14. McKenzie, S. Social Sustainability: Towards some Definitions; Hawke Research Institute Working Paper Series No 27; Hawke Research Institute University of South Australia: Magill, SA, Australia, 2004.

15. Rasouli, A.H.; Kumarasuriyar, A. The social dimention of sustainability: Towards some definitions and analysis. J. Soc. Sci. Policy Implications 2016, 4, 23-34. [CrossRef]

16. Colantonio, A. Social sustainability: A review and critique of traditional versus emerging themes and assessment methods. In Proceedings of the SUE-Mot Conference 2009: Second International Conference on Whole Life Urban Sustainability and its Assessment, Loughborough, UK, 22-24 April 2009; Horner, M., Price, A., Bebbington, J., Emmanuel, R., Eds.; Loughborough University: Loughborough, UK, 2009; pp. 865-885.

17. Åhman, H. Social sustainability-Society at the intersection of development and maintenance. Local Environ. 2013, 18, 1153-1166. [CrossRef]

18. Chalip, L. Towards social leverage of sport events. J. Sport Tour. 2006, 11, 109-127. [CrossRef]

19. Rogers, D.S.; Duraiappah, A.K.; Antons, D.C.; Munoz, P.; Bai, X.; Fragkias, M.; Gutscher, H. A vision for human well-being: Transition to social sustainability. Curr. Opin. Environ. Sustain. 2012, 4, 61-73. [CrossRef]

20. De Bres, K.; Davis, J. Celebrating group and place identity: A case study of a new regional festival. Tour. Geogr. 2001, 3, 326-337. [CrossRef]

21. Finkel, R. "Dancing around the Ring of Fire": Social capital, tourism resistance, and gender dichotomies at Up Helly Aa in Lerwick, Shetland. Event Manag. 2010, 14, 275-285. [CrossRef]

22. Gursoy, D.; Kim, K.; Uysal, M. Perceiving impacts of festivals and special events by organizers: An extension and validation. Tour. Manag. 2004, 25, 171-181. [CrossRef]

23. Negruşa, A.L.; Toader, V.; Rus, R.V.; Cosma, S.A. Study of perceptions on cultural events' sustainability. Sustainability 2016, 8, 1269. [CrossRef]

24. Deery, M.; Jago, L. Social impacts of events and the role of anti-social behaviour. Int. J. Event Festiv. Manag. 2010, 1, 8-28. [CrossRef]

25. Small, K. Social dimensions of community festivals: An application of factor analysis in the development of the social impact perception (SIP) scale. Event Manag. 2007, 11, 45-55. [CrossRef]

26. Arcodia, C.; Whitford, M. Festival attendance and the development of social capital. J. Conv. Event Tour. 2006, 8, 1-18. [CrossRef]

27. Quinn, B.; Wilks, L. Festival connections: People, place and social capital. In Exploring the Social Impacts of Events; Richards, G., de Brito, M.P., Wilks, L., Eds.; Routledge: Abingdon, UK, 2013; pp. 15-30.

28. Quinn, B.; Wilks, L. Linking social capital, cultural capital and heterotopia at the folk festival. J. Comp. Res. Anthropol. Sociol. 2016, 7, 23-39.

29. Wilks, L. Bridging and bonding: Social capital at music festivals. J. Policy Res. Tour. Leis. Events 2011, 3, 281-297. [CrossRef]

30. Rihova, I.; Buhalis, D.; Moital, M.; Gouthro, M.-B. Social constructions of value: Marketing considerations for the context of event and festival visitation. In Ideological, Social and Cultural Aspects of Events; Moufakkir, O., Pernecky, T., Eds.; CABI International: Wallingford, UK, 2015; pp. 74-85.

31. Jordan, J. The festivalisation of contemporary life. In Focus on World Festivals: Contemporary Case Studies and Perspectives; Newbold, C., Jordan, J., Eds.; Goodfellow: Oxford, UK, 2016; pp. 6-18.

32. Kinnunen, M.; Uhmavaara, K.; Jääskeläinen, M. Evaluating the brand image of a rock festival using positive critical incidents. Int. J. Event Festiv. Manag. 2017, 8, 186-203. [CrossRef]

33. Páez, D.; Rimé, B. Collective emotional gatherings: Their impact upon identity fusion, shared beliefs, and social integration. In Collective Emotions: Perspectives from Psychology, Philosophy, and Sociology; von Scheve, C., Salmela, M., Eds.; Oxford University Press: Oxford, UK, 2014; pp. 204-216.

34. Hassanli, M.; Walters, T.; Williamson, J. "You feel you're not alone": How multicultural festivals foster social sustainability through multiple psychological sense of community. J. Sustain. Tour. 2020, 1-8. [CrossRef]

35. Duffy, M.; Waitt, G. Rural festivals and processes of belonging. In Festival Places: Revitalising Rural Australia; Gibson, C., Connell, J., Eds.; Channel View: Bristol, UK, 2011; pp. 44-57.

36. Putnam, R.D. Bowling Alone: The Collapse and Revival of American Community; Simon \& Schuster: New York, NY, USA, 2000.

37. Getz, D. Event Studies: Theory, Research and Policy for Planned Events; Elsevier: Amsterdam, The Netherlands, 2007.

38. Ziakas, V. Fostering the social utility of events: An integrative framework for the strategic use of events in community development. Curr. Issues Tour. 2016, 19, 1136-1157. [CrossRef] 
39. Turner, V. The Ritual Process: Structure and Anti-Structure; Aldine Transaction: New Brunswick, NJ, USA, 2008. (Original edition 1969.).

40. Maffesoli, M. The Time of the Tribes: The Decline of Individualism in Mass Society; SAGE: London, UK, 1997. (Original edition 1988.).

41. Cavicchi, D. Tramps Like Us: Music and Meaning Among Springsteen Fans; Oxford University Press: New York, NY, USA, 1998.

42. Kahn-Harris, K. Extreme Metal: Music and Culture on the Edge; Berg: Oxford, UK, 2007.

43. Saarikallio, S.; Erkkilä, J. The role of music in adolescents' mood regulation. Psychol. Music 2007, 35, 88-109. [CrossRef]

44. McMillan, D.W.; Chavis, D.M. Sense of community: A definition and theory. J. Community Psychol. 1986, 14, 6-23. [CrossRef]

45. Rowe, P. "We're in this together and we take care of our own": Narrative constructions of metal community told by metal youth. In Heavy Metal Music and the Communal Experience; Varas-Díaz, N., Scott, N., Eds.; Lexington Books: Lanham, UK, 2016; pp. 79-98.

46. Cochrane, T. Joint attention to music. Br. J. Aesthet. 2009, 49, 59-73. [CrossRef]

47. Wood, E.H.; Kinnunen, M. Emotion, memory and re-collective value: Shared festival experiences. Int. J. Contemp. Hosp. Manag. 2020, 32, 1275-1298. [CrossRef]

48. Beccaria, F.; Sande, A. Drinking games and rite of life projects: A social comparison of the meaning and functions of young people's use of alcohol during the rite of passage to adulthood in Italy and Norway. Young 2003, 11, 99-119. [CrossRef]

49. Official Statistics of Finland (OSF). Participation in Leisure Activities. Available online: http://www.stat.fi/til/ vpa/tau_en.html (accessed on 27 October 2020).

50. LiveFIN Festivaalien Liikevaihto oli Vielä Viime Vuonna 192 Miljoonaa Euroa [The Revenue from Festivals was 192 Million Euros Last Year]. Available online: http://www.livefin.fi/festivaalien-toimialatutkimus/ (accessed on 27 October 2020).

51. TENK. Ihmiseen Kohdistuvan Tutkimuksen Eettiset Periaatteet ja Ihmistieteiden Eettinen Ennakkoarviointi Suomessa [Ethical Principles of Research in the Humanities and Social and Behavioural Sciences and Proposals for Ethical Review]; National Advisory Board on Research Ethics (TENK): Helsinki, Finland, 2019.

52. Sax, L.J.; Gilmartin, S.K.; Lee, J.J.; Hagedorn, L.S. Using web surveys to reach community college students: An analysis of response rates and response bias. Community Coll. J. Res. Pract. 2008, 32, 712-729. [CrossRef]

53. Smith, W.G. Does Gender Influence Online Survey Participation?: A Record-Linkage Analysis of University Faculty Online Survey Response Behavior, Research Report; San José State University: San José, CA, USA, 2008.

54. Sugarigrandi Why Women Use Social Media More in 2020? Medium, 18 February 2020. Available online: http://medium.com/@sugarigrandi/why-women-use-social-media-more-in-2020-29a869ac1f92 (accessed on 27 October 2020).

55. Krippendorff, K. Content Analysis: An Introduction to Its Methodology; Sage: Thousand Oaks, CA, USA, 2004.

56. Hill, J.A. Endangered childhoods: How consumerism is impacting child and youth identity. Media Cult. Soc. 2011, 33, 347-362. [CrossRef]

57. Hallamaa, T.; Vedenpää, V. Nuoret Rynnivät Suurkonsertteihin ja Samalla Rock-Klubit Sulkevat Oviaan: "Spotify-Aika Ajaa Massatapahtumiin" [Young People Rush to Big Concerts and at the Same Time Rock Clubs are Closing Down: "Spotify Time Leads to Mass Events"]. Yle, 22 October 2019. Available online: http://yle.fi/uutiset/3-11026712 (accessed on 27 October 2020).

58. De Geus, S. Investigating the effect of group size in event experiences. In Exploring the Social Impacts of Events; Richards, G., de Brito, M.P., Wilks, L., Eds.; Routledge: Abingdon, UK, 2013; pp. 157-173.

59. O'Connor, A. Local scenes and dangerous crossroads: Punk and theories of cultural hybridity. Pop. Music 2002, 21, 225-236. [CrossRef]

60. Polése, M. Learning from each other: Policy choices and the social sustainability of cities. In The Social Sustainability of Cities: Diversity and the Management of Change; Polése, M., Stren, R., Eds.; University of Toronto Press: Toronto, ON, Canada, 2000; pp. 308-334.

61. DeNora, T. Music Asylums: Wellbeing Through Music in Everyday Life; Ashgate: Farnham, UK, 2013.

62. Krueger, J. Affordances and the musically extended mind. Front. Psychol. 2014, 4, 1003. [CrossRef]

63. Saarikallio, S. Music as emotional self-regulation throughout adulthood. Psychol. Music 2010, 39, 307-327. [CrossRef] 
64. Sun, H.; Wu, S.; Li, Y.; Dai, G. Tourist-to-tourist interaction at festivals: A grounded theory approach. Sustainability 2019, 11, 4030. [CrossRef]

65. Volgsten, U.; Pripp, O. Music, memory, and affect attunement: Connecting Kurdish diaspora in Stockholm. Cult. Unbound 2016, 8, 144-164. [CrossRef]

66. Salmela, M. Shared emotions. Philos Explor. 2012, 15, 33-46. [CrossRef]

67. Karlsson, K.P.; Sikström, S.; Jönsson, F.U.; Gustafsson Sendén, M.; Willander, J. Gender differences in autobiographical memory: Females latently express communality more than do males. J. Cogn. Psychol. 2019, 31, 651-664. [CrossRef]

68. Eichenberger, K. Gender differences in the use of gay clubs: A place to resist gender norms for gay men and a place of diffusion for lesbian women. J. Undergrad. Ethnography 2012, 2, 4-20. [CrossRef]

69. Hänninen, J. The Four Stages of a DIY Career: The Life Courses and Careers of Youth Culture Practitioners from Lepakkoluola and the Helsinki Scene of the Early 1980s. Master's Thesis, University of Helsinki, Helsinki, Finland, 2019.

70. Maani, K.E.; Cavana, R.Y. Systems Thinking and Modelling: Managing Change and Complexity, 2nd ed.; Pearson Education: Auckland, New Zealand, 2007.

71. Bennett, A.; Guerra, P. Rethinking DIY culture in a post-industrial and global context. In DIY Cultures and Underground Music Scenes; Bennett, A., Guerra, P., Eds.; Routledge: Abingdon, UK, 2019; pp. 7-18.

72. Haenfler, R. The entrepreneurial (straight) edge: How participation in DIY music cultures translates to work and careers. Cult. Sociol. 2018, 12, 174-192. [CrossRef]

73. Morris, J.W.; Powers, D. Control, curation and musical experience in streaming music services. Creat. Ind. J. 2015, 8, 106-122. [CrossRef]

74. Marshall, L. "Let's keep music special. F-Spotify": On-demand streaming and the controversy over artist royalties. Creat. Ind. J. 2015, 8, 177-189. [CrossRef]

75. Buckingham, D. The commercialisation of childhood? The place of the market in children's media culture. Chang. Engl. 1995, 2, 17-40. [CrossRef]

76. Baxter, S. Helsinki's Huge VR Gig Hints at the Potential of Virtual Tourism. The Guardian, 5 May 2020. Available online: http://www.theguardian.com/travel/2020/may/05/helsinki-huge-vr-virtual-reality-gigpotential-virtual-tourism (accessed on 30 October 2020).

77. Millman, E. The New Reality for Concerts in COVID: Virtual Reality? RollingStone, 1 July 2020. Available online: http://www.rollingstone.com/pro/features/virtual-reality-livestreams-covid-1021683/ (accessed on 31 October 2020).

Publisher's Note: MDPI stays neutral with regard to jurisdictional claims in published maps and institutional affiliations.

(C) 2020 by the authors. Licensee MDPI, Basel, Switzerland. This article is an open access article distributed under the terms and conditions of the Creative Commons Attribution (CC BY) license (http://creativecommons.org/licenses/by/4.0/). 